\title{
O pensamento de Paulo Freire expresso na obra Pedagogia da Indignação: cartas pedagógicas e outros escritos
}

\author{
Paulo Freire's thought expressed in the work Pedagogia da \\ Indignação: cartas pedagógicas e outros escritos
}

\section{El pensamiento de Paulo Freire expresado en la obra Pedagogia da Indignação: cartas pedagógicas e outros escritos}

\author{
Amancio Leandro Corrêa Pimentel'

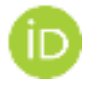 \\ https://orcid.org/0000-000I-6237-26I7 \\ Antônia Solange Pinheiro Xerez ${ }^{2}$ \\ https://orcid.org/0000.000I-6479-65IX \\ Francisco Mirtiel Frankson Moura Castro 3 \\ https://orcid.org/0000-0002-8685-9857
}

Resumo: Por intermédio da análise e reflexão da obra Pedagogia da indignação: cartas pedagógicas e outros escritos, de Paulo Freire, o estudo propõe-se discutir, em caráter introdutório, sobre assuntos vigentes e pertinentes na realidade brasileira, como formação de consciência democrática e ética, ante discursos antidemocráticos e da subordinação à "ética" do mercado; história como possibilidade, em contraposição a história como determinismo; e a necessária leitura e uso críticos da tecnologia e meios de comunicação ante a globalização neoliberal atrelada aos seus discursos ideológicos. A abordagem deste estudo é de natureza qualitativa, fundamentada em pesquisa bibliográfica, dando destaque ao livro supracitado, sem omitir, contudo, seu diálogo

\footnotetext{
' Mestre em Educação e Ensino pelo Mestrado Acadêmico Intercampi em Educação e Ensino (MAIE) da Universidade Estadual do Ceará (UECE). Especialista em Gestão Escolar pela Universidade Regional do Cariri (URCA) e graduado em Pedagogia (URCA). Professor efetivo da Educação Básica pela Secretaria Municipal de Educação, Crato-CE. Professor do Ensino Superior pelo Plano Nacional de Formação de Professores (PARFORURCA). E-mail: pimentelalc@gmail.com

${ }^{2}$ Pós-Doutora em Educação pela Universidade Federal do Ceará (UFC). Doutora em Educação pela Universidade Nove de Julho (UNINOVE). Professora do curso de Pedagogia do Centro de Educação da UECE e do Mestrado Acadêmico Intercampi de Educação e Ensino MAIE/UECE. E-mail: antonia.xerez@uece.br

${ }^{3}$ Pós-Doutor em Educação pela Universidade Federal do Ceará (UFC). Doutor em Educação pela Universidade Estadual do Ceará (UECE). Professor do curso de Licenciatura em Pedagogia e do Programa de Pós-Graduação em Educação da UECE. E-mail: mirtielfrankson@gmail.com
}

Olhar de professor, Ponta Grossa, v. 24, p. I-2I, e-I6723.0 I3, 202 I.

Disponível em <https://revistas2.uepg.br/index.php/olhardeprofessor> 
e coerência com os escritos de Freire no decurso de sua obra. Depreende-se nestes escritos de Freire provocação à indispensável leitura da realidade e seus temas vigentes, complexos, em sua relação com os conteúdos curriculares como imprescindíveis à inserção na história na qualidade de presença ativa.

Palavras-chave: Paulo Freire. Pedagogia da Indignação. Mudança da realidade.

Abstract: Through of the analysis of the work Pedagogia da indignação: cartas pedagógicas e outros escritos, by Paulo Freire, the study propose to discuss, on an introdutory basis, on current and pertinente issues in the Brazilian reality, such as the formation of democratic and ethnical conscience, before anti-democratics speeches and the subordination to the "ethics" of the Market; the history as a possibility, in contrast to a history determinism; and the necessary critical reading and use of the technology and means of communication in the face of neoliberal globalization linked to their ideological discourses. The approach of this study is of a qualitative nature, based on bibliographic research, highlighting the book mentioned above, without omitting, however, its dialogue and coherence with Freire's writings in the course of his work. Freire's writings provoke the indispensable reading of reality and its current, complex themes, in their relationship with the curricular contents, as essential to the insertion in history as an active presence.

Keywords: Paulo Freire. Pedagofy of indignation. Reality change.

Resumen: Por el intermedio del análisis y reflexión de la obra Pedagogia da indignação: cartas pedagógicas e outros escritos, de Paulo Freire, el estudio se propone a discutir, en carácter inicial, temas vigentes y pertinentes en la realidad brasileña, como formación de consciencia democrática y ética, ante discursos antidemocráticos y de la subordinación a la "ética" del mercado; historia como posibilidad, en contraposición a historia como determinismo; y a necesaria lectura y uso críticos de la tecnología y medios de comunicación frente a globalización neoliberal unida a sus discursos ideológicos. El abordaje de este estudio tiene naturaleza cualitativa, con fundamentación en investigación bibliográfica, con el enfoque en el libro supra citado, sin omitir, sin embargo, su diálogo y coherencia con los escritos de Freire en el decurso de su obra. Se deduce en estos escritos de Freire provocación a la indispensable lectura de la realidad y sus temas vigentes, complejos, en su relación con los contenidos curriculares como imprescindibles a la inserción en la historia en la calidad de presencia activa.

Palabras-clave: Paulo Freire. Pedagogía de la indignación. Cambio en la realidad.

\title{
Introdução
}

\begin{abstract}
A desproblematização do futuro, não importa em nome de que, é uma ruptura com a natureza humana, social e historicamente construindo-se. O futuro não nos faz. Nós é que nos refazemos na luta para fazê-lo.
\end{abstract}

(Paulo Freire, 2015, p. 65).

A obra de Paulo Freire sempre esteve - usando seus termos - "molhada" de uma percepção problematizadora do mundo, da história, do futuro. Tal percepção, por sua vez, encontra base na evidenciação do inacabamento humano que se estende à constituição da realidade. Freire não aceita a percepção determinista de história que defende seu fim e, portanto, mera adaptação e passividade. Ante essa premissa, o estudo que ora se relata intenciona pensar sobre essa atitude de Freire em seus escritos, mais detidamente no livro póstumo Pedagogia da indignação: cartas pedagógicas e outros escritos.

O livro de Paulo Freire sobre o qual nos debruçamos, tecendo reflexões, mesmo que em caráter introdutório, é composto por nove textos divididos em duas partes. Na primeira parte - Cartas pedagógicas - encontra-se os três últimos escritos de Freire, de janeiro e abril de 1997, e, na segunda - Outros escritos - um texto de 1992 e cinco textos de 1996. Este livro foi organizado por Ana Maria 
Amancio Leandro Corrêa Pimentel, Antônia Solange Pinheiro Xerez e Francisco Mirtiel Frankson Moura Castro

Araújo Freire (esposa e viúva do mencionado autor), que teve o cuidado de escolher um nome para a obra que expressa a relevância do teor dos textos, Pedagogia da indignação: cartas pedagógicas e outros escritos.

A escolha dessa publicação para esta exposição se justifica na pertinência das análises de Freire em relação a temas que hoje ainda fazem parte do cotidiano brasileiro, dentre os quais, se destaquem, a formação de consciência democrática em dias de discursos notadamente antidemocráticos, a "ética" de mercado em contraposição à ética universal do ser humano, a coisificação do humano, neoliberalismo, história inacabada, abertura lúcida ao novo e outros. O interesse é de se de ter nesse livro um meio de análise que denota potencial para estimular e subsidiar a busca por conhecimento da realidade e dos temas vigentes em sua complexidade, bem como a necessidade de se assumir como presença interventora na elaboração da história.

Assim, por meio da análise e reflexão do trabalho mencionado de Paulo Freire, o estudo propõe-se discutir assuntos vigentes e pertinentes na realidade brasileira, como formação de consciência democrática e ética ante discursos antidemocráticos e subordinação à "ética" do mercado; história como possibilidade, em contraposição a história como determinismo; e a necessária leitura e uso críticos da tecnologia e meios de comunicação perante a globalização neoliberal.

A abordagem deste ensaio é de natureza qualitativa uma vez que trabalha com o universo " [...] dos significados, motivos, aspirações [...] o que corresponde a um espaço mais profundo das relações, dos processos, dos fenômenos que não podem ser reduzidos a operacionalizações variáveis" (DESLANDES et al., 1994, p. 21). Movidos pela necessidade de pensar a educação na relação indicotomizável com a realidade mais abrangente constituída "[...] de objetos e fenômenos organicamente ligados entre si [...] condicionando-se reciprocamente" (LAKATOS; MARCONI, 2003, p. (0I), transitamos no interior de uma opção teórico-metodológica dialética na medida em que, ao modo do corpus teórico freireano, reconhecemos nas relações homens-mundo uma “[...] inquebrantável solidariedade [...]" (FREIRE, 1980, p. 97) que "[...] leva à necessidade de avaliar uma situação, um acontecimento, uma tarefa, uma coisa, do ponto de vista das condições que os determinam e, assim, os explicam" (LAKATOS; MARCONI, 2003, p. I0I). Optamos pela pesquisa bibliográfica, considerando a crítica textual externa e interna aos textos estudados (LAKATOS; MARCONI, 2003), cuja intenção foi analisar e dar destaque especial a obra Pedagogia da indignação: cartas pedagógicas e outros escritos. Com efeito, conquanto buscamos nos ater à referida obra, evidenciou-se, todavia - nos processos de análise e interpretação - que as categorias e temas expressos em Pedagogia da indignação dialogam e mantêm coerência com a obra de Freire (1980, I98I, 20I la, $20 \mathrm{Ilb}, 20 \mathrm{I} 4 \mathrm{a})$ expressa ao correr de seus escritos que foram, por sua vez, reexaminados para $\circ$ presente texto.

Olhar de professor, Ponta Grossa, v. 24, p. I-2I, e-16723.013, 2021.

Disponível em <https://revistas2.uepg.br/index.php/olhardeprofessor> 
O pensamento de Paulo Freire expresso na obra Pedagogia da Indignação: cartas pedagógicas e outros escritos

$\mathrm{Na}$ apresentação do livro sob comento, em sua segunda edição, com data de II de fevereiro de 2000, publicada pela UNESP (Universidade Estadual Paulista Júlio de Mesquita Filho), aqui analisado (2015), Ana Freire (conhecida como Nita), relata a profunda dor que foi, depois do falecimento de seu marido, ler e pensar na publicação dos últimos escritos dele. Ela relata que "[...] era como se isso fosse confirmar o fato consumado de sua ausência, tão doloroso quanto irreversível" (apud FREIRE, 20I5, p. 10). Com o passar do tempo, entretanto, e com a atenuação da dor expressa pelo falecimento de Freire, considerou que sua publicação era importante, visto que tais escritos "[...] são fundamentais para quem estuda a obra freiriana, tanto por nele estarem, de fato, suas últimas reflexões escritas como pela importância e modo de abordagem dos temas tratados" (apud FREIRE, 2015, p. II).

De acordo com Ana Freire, quando Paulo se propôs escrever o novo livro, a escolha do nome já havia sido realizada e seria Cartas pedagógicas. Em razão, todavia, da pouca quantidade de páginas deixadas, Ana Freire fez uma busca por textos ainda não publicados que - adicionados aos manuscritos - vieram a ser editados no livro com o retro mencionado título. $\mathrm{Na}$ justificativa da escolha do título, a autora argumenta que, "Como em todos estes textos escolhidos para compor este livro Paulo demonstra a sua indignação, a sua legítima raiva e a sua generosidade de amar, resolvi que o título do livro deveria corresponder a essa sua permanente atitude ante a vida [...]" (apud FREIRE, 20I5, p. I3).

De fato, constata-se na leitura da obra, que Freire, até seus últimos escritos, manteve posição antagônica à lógica perversa que rege e deturpa a "ética" e a "democracia" - pautadas pelo mercado presentes na sociedade. São textos de veemente denúncia e anúncio. Denúncia do império da lógica mercadológica, que reduz as pessoas a coisas; que se alastra pelas relações interpessoais; que se exprime como isento e neutro, "matando" o sonho, a esperança; e é anúncio da história como inacabada, portanto, da história como possibilidade, da necessidade de formação de consciência autenticamente democrática, da imprescindível importância de ascensão de valores assentes na ética universal do ser humano - e não pela lógica do mercado - como fundamentais ao estabelecimento de um mundo que respeite a vida em sua dimensão humana, animal e natural. Portanto, vemos um Freire muito "vivo", esperançoso, cheio de vigor e ânimo, conforme destaca o professor da Universidade Federal do Rio Grande do Sul, Balduíno A. Andreola, no prefácio cuja leitura integral recomendamos e do qual vale destacar dois elementos que consideramos interessante a nossa proposição.

Em primeiro lugar, o mencionado ânimo e disposição, ante o mundo, que esteve em Freire até - ultimo dia da sua vida. Andreola, como se estivesse respondendo a uma carta de Freire, diz que a leitura dos referidos textos foi "[...] como a imersão numa imensa onda cósmica de ânimo, de esperança e do sentimento de que vale a pena persistir na luta" (apud FREIRE, 20I5, p. 18) e se refere à perseverança de Freire como "perseverança perene" (apud FREIRE, 20I5, p. 19). O livro, como um todo, mostra essa disposição do "menino" que há em Paulo Freire, militante pela transformação da

Olhar de professor, Ponta Grossa, v. 24, p. I-21, e-16723.013, 2021.

Disponível em <https://revistas2.uepg.br/index.php/olhardeprofessor> 
Amancio Leandro Corrêa Pimentel, Antônia Solange Pinheiro Xerez e Francisco Mirtiel Frankson Moura Castro sociedade, evidenciando a necessidade de criação de um mundo autenticamente justo. Ele foi preso, exilado, ficou anos fora do Brasil e, mesmo assim, na luta, em meio a necessidades diversas, mantevese animado e perseverante.

Outro elemento fundamental, pontuado pelo prefaciador, é que, na produção de Paulo Freire sempre houve a ênfase na ideia de que precisamos de uma realidade diferente, que não seja marcada pela ganância, pelo lucro, fundamentada no desamor. Portanto, para Freire, esse mundo precisa ser reconstituído. E, entretanto, aqui está o destaque do autor do prefácio, pois é preciso que se vença uma tendência da ideologia e do discurso dominante, que é a de estimular a retirada das pessoas, das classes populares, do debate sobre ética, política, democracia e estabelecimento do mundo.

Paulo Freire anuncia que, para viabilizar outra realidade, é preciso que se anuncie, concomitantemente, "[...] o direito das classes populares de participar dos debates em torno de um projeto de mundo" (apud FREIRE, 20I5, p. 25), ou seja, todos precisam participar de tal elaboração. Portanto, a sociedade como um todo é convocada a debater sobre ética, acerca de relações e a respeito de política, indo na contramão do modismo, ao dizer "que não tem mais sentido, na pósmodernidade, falar as linguagens da ética e da política, superadas pelos 'delírios' da globalização e da internet" (apud FREIRE, 20I5, p. 23).

Com efeito, é preciso que a classe trabalhadora e oprimida esteja nesse debate e nessa reconstituição, o que demonstra a tônica da pedagogia de Freire expressa em toda sua obra, desde Educação como prática da liberdade (FREIRE, 198I), escrita em 1965, passando pela Pedagogia do oprimido (FREIRE, 1980) ao lume em 1968 e demais livros, chegando aos seus últimos escritos em 1997, em um percurso de mais de três décadas de produção editorial.

Freire sempre se colocou como defensor da participação do povo, das classes populares, dos esfarrapados do mundo, na captação dos temas vigentes dos momentos históricos para sua inserção no pronunciamento do mundo, em diálogo autêntico (FREIRE, 1980) como condição imprescindível à feitura de um mundo mais justo. Só partindo da perspectiva do oprimido, é possível a criação de uma realidade menos violenta em sua estrutura. Daí de ser realizada a leitura do Prefácio.

Para a tessitura e reflexão proposta neste artigo, em vez de comentários separados sobre cada um dos nove textos, optamos por organizar o ensaio em três blocos de temas principais, que se depreendem da interpretação das ideias sob exame. São eles: Ética, democracia e educação; História, formulação da realidade e educação; e Globalização, tecnologia e educação.

Embora tais temas se cruzem na obra como um todo, em torno das categorias mercado, neoliberalismo, política e utopia, é notório o fato de que, em relação ao primeiro tema, constata-se maior discussão na primeira carta - Do espírito deste livro - juntamente com a terceira carta - Do assassinato de Galdino Jesus do Santos-índio Pataxó - e o texto - Descobrimento da América. Em relação ao segundo 
O pensamento de Paulo Freire expresso na obra Pedagogia da Indignação: cartas pedagógicas e outros escritos tema, temos uma prevalência na segunda carta - Do direito e do dever de mudar o mundo - e nos textos: Alfabetização e miséria; Educação e esperança e Denúncia, anúncio, profecia, utopia e sonho. Finalmente, o terceiro tema se vê mais nos textos Desafios da educação de adultos ante a nova reestruturação tecnológica e $A$ alfabetização em televisão. Enfatizemos, contudo, mais uma vez, esses assuntos estão no livro, todo e a referida sistematização é adotada aqui, sobretudo, para fins de melhor compreensão da obra.

\title{
Ética, democracia e educação
}

No primeiro segmento - Do espírito deste livro - Freire (2015) começa pela reflexão acerca da democracia e da formação de consciência democrática. Ele parte da seguinte premissa: a realidade vigente se arrima numa "ética" e numa "democracia" de mercado. A rigor, ética e democracia não são conceitos adequados ao mercado, porque ambos dizem respeito ao humano, partindo do humano, de suas inter-relações e de seu comportamento perante o outro. Na coisificação (reificação) do humano, no entanto, Freire se utiliza dessas expressões, "ética" e "democracia" de mercado para denunciar processos de desumanização.

Portanto, enfatiza a noção de que, para a transformação do mundo, não se pode abster da luta pelo estabelecimento de ética e da democracia que partam do humano e para o humano se voltem. Urge, assim, a necessidade de agora, hoje, sempre, lutar por constituir uma autêntica consciência democrática na sociedade, desde a infância e juventude. Freire diz:

\begin{abstract}
Um dos meus sonhos ao escrever essas cartas pedagógicas - se não os tivesse não haveria porque escrevê-las - é desafiar-nos, pais e mães, professores e professoras, operários, estudantes, a refletir sobre o papel que temos, e a responsabilidade de assumi-lo bem, na construção e no aperfeiçoamento da democracia entre nós. Não de uma democracia que aprofunda as desigualdades, puramente convencional, que fortifica o poder dos poderosos, que assisti de braços cruzados à aviltação e ao destrato dos humildes e que acalenta a impunidade. (FREIRE, 20I5, p. 54).
\end{abstract}

Ressaltemos que, para Freire (20I5), transformações genuínas devem ocorrer em níveis estrutural e superestrutural, subjetivo e objetivo. Portanto, a elaboração e o aperfeiçoamento da democracia e da ética se posicionam como alguns dos muitos elementos imprescindíveis da transformação da realidade. A fim de tratar da formação de consciência democrática, o autor lança mão de vários conceitos, dentre os quais destacamos: liberdade, autoridade, escolha e decisão. Sem o devido trabalho com esses conceitos, dificilmente se alcançará sucesso na formação de pessoas autenticamente democráticas. Vejamos de modo breve estes termos a seguir.

Liberdade e autoridade são conceitos que facilmente se desdobram em extremos e distorções. Por exemplo, a liberdade pode virar licenciosidade. Freire (2015, p. 37) expõe a noção de que "[...] é preciso, inclusive, deixar claro, em discursos lúcidos, e em práticas democráticas, que a vontade só se autentica na ação de sujeitos que assumem seus limites”, assim, “[...] a vontade ilimitada é a vontade 
Amancio Leandro Corrêa Pimentel, Antônia Solange Pinheiro Xerez e Francisco Mirtiel Frankson Moura Castro despótica, negadora de outras vontades e, rigorosamente, de si mesma" (FREIRE, 2015, p. 37), liberdade que distorcida em licenciosidade se transforma contraditoriamente em "tirania da liberdade" (FREIRE, 2015, p. 37).

A distorção da autoridade, por sua vez, o autoritarismo, que se fundamenta na crença de que determinados princípios e valores são superiores aos do outro, impondo, portanto, vontades e ideias e castrando vozes, visões e discursos diferentes - opera violência e invasão. Assim, a "[...] tirania, a da autoridade, em que as crianças caladas, cabisbaixas, 'bem-comportadas', submissas nada podem" (FREIRE, 20I5, p. 39) é um tema relevante para o autor. Liberdade e autoridade, sendo experimentadas em equilíbrio, verificam-se não antagônicas uma da outra e somente dentro dessa tensão, autêntica e equilibrada, se pode falar em decisão, escolha e, portanto, em formação de consciência democrática.

Os conceitos de escolha e decisão, a seu turno, são fundamentais na percepção equilibrada da tensão autoridade-liberdade. Vale lembrar que na vida sempre se colocará a necessidade de escolher e decidir sobre algo, desde aspectos pequenos a grandes. "Qual desenho que eu assisto?" Que música? "Qual é a luta que eu vou travar?" "Qual é o tipo de pessoa quero para fazer parte da minha vida?" "Quais são os governantes que queremos que governem o nosso país?" Não tem como fugir de ter que escolher e decidir. Não há neutralidade! A não escolha é uma escolha.

Com efeito, Paulo Freire (2015), portanto, evidencia que, para trabalhar esses quatro conceitos, ao menos duas dimensões são necessárias. Primeiro, o bom testemunho dos adultos, dos professores, dos pais, mães, das professoras, ou seja, testemunho do compromisso com a educação, com a ética, com o profissionalismo, com um mundo justo, com o respeito ao outro, ao Planeta, à natureza. $O$ outro elemento é a oportunidade que se dá às crianças, desde pequenas, para que possam exercitar sua liberdade, a convivência com a autoridade, a fundamentação em si da capacidade de escolher e decidir.

Ao fazer essas observações, Freire (2015) não está ignorando a verdade segundo a qual nossa sociedade, estruturalmente perversa, por vezes, inviabiliza valores e princípios minimamente necessários ao crescimento saudável da pessoa. Como ser coerente, dar bom testemunho, lutar por um mundo justo, estando-se em situações de miséria, fome, violência física, psíquica e simbólica, em coerções patronais que estimulam veladamente à competitividade, a mentira, o "passar a perna" no outro em nome de uma possível demissão ou dispensa por falta de "produtividade" no "trabalho"?

Depreende-se que nosso desafio se evidencia como gritante e muito expressivo em face da realidade supracitada. Impõe-se, portanto a esperança, fundada na concepção da história como inconclusa na busca pela transformação social. Não é porque a dificuldade (com ares de inexorabilidade) se coloca, que não se vai lutar contra ela, discutindo temas necessários, como formação de consciência democrática e ética, sempre problematizando-os. A escola pública, portanto,

Olhar de professor, Ponta Grossa, v. 24, p. I-21, e-16723.013, 2021.

Disponível em <https://revistas2.uepg.br/index.php/olhardeprofessor> 
O pensamento de Paulo Freire expresso na obra Pedagogia da Indignação: cartas pedagógicas e outros escritos que trabalha com alunos e alunas em situações extremas de desigualdade social, se expressa como espaço privilegiado para lidar com os desafios propostos por Freire (2015). A luta pela escola pública, por isso, estruturada, acolhedora, com alimentação abundante, integral, com salas menos lotadas, com docentes formados política, científica e pedagogicamente, se exprime como luta pela constituição de valores e princípios necessários à conformação de outra realidade.

Voltando... É preciso, portanto, dar voz à criança, manter um constante estimulo à pergunta, ao debate, para que tais princípios sejam trabalhados desde a infância. Não se há de esperar que pessoas criadas protegidas do contraditório, em um estado de resguardo de situações que demandem liberdade, autoridade, escolha e decisão, quando adultas, saberão magicamente lidar com situações éticas e, portanto, democráticas e políticas. Nesse ponto, Freire diz: “[...] submetidas ao rigor sem limites da autoridade arbitrária as crianças experimentam fortes obstáculos ao aprendizado da decisão, da escolha, da ruptura” (FREIRE, 2015, p. 37). E prossegue: “[...] como aprender a decidir, proibidas de dizer a palavra, de indagar, de comparar" (FREIRE, 20I5, p. 37) e, por outro lado, “[...] como aprender democracia na licenciosidade em que, sem nenhum limite a liberdade faz o que quer ou no autoritarismo em que, sem nenhum espaço, a liberdade jamais se exerce?" (FREIRE, 20I5, p. 37).

O discurso de que à escola só cabe a instrução meramente técnica e curricular não se sustenta, porque o humano existe, e, junto com ele, têm curso relações, conflitos, amizades, escolhas, decisões, diálogo etc. Além da insustentabilidade de uma percepção asséptica de educação, é preciso que se faça a denúncia de que tal discurso opera em favor do empobrecimento do processo educacional e na omissão do trabalho com ética e relações humanas, favorecendo à lógica da coisificação. Tal lógica de coisificação de tudo e das pessoas leva Freire (2015) a uma reflexão indignada acerca do caso do assassinato de Galdino, índio pataxó, por cinco adolescentes em abril de 1997. Observa-se no pequenino texto - Do assassinato de Galdino Jesus do Santos-índio Pataxó, o último escrito do autor, de 2 I de abril - o tom de perplexidade.

Sem retirar a culpa dos adolescentes - Freire (2015) reflete sobre como esses adolescentes cresceram e reúne os seguintes - e necessários - pontos que por muitas vezes se ignora: do que eles brincavam? De estrangular pintinhos? De colocar fogo no rabo do gato? De esmigalhar plantas? Do que eles brincavam? Qual foi o testemunho que eles receberam do pai, da mãe, das pessoas adultas que estavam ao seu redor, de como tratar e como lidar com as pessoas? Que exemplos expectaram sobre como pensar sobre o negro, o indígena, o pobre, a pessoa que pensa diferente? Será que esses adultos foram omissos? Ou até estimularam coisas assim?

Em sua reflexão ampla, Freire não pretende colocar um "peso" nas costas de pais, mães e demais adultos, que muitas vezes fazem tudo o que podem pela educação dos mais jovens e terminam "perdendo" para a influência alienadora dos meios de comunicação de massa e de outros contextos

Olhar de professor, Ponta Grossa, v. 24, p. I-2I, e-16723.013, 2021.

Disponível em <https://revistas2.uepg.br/index.php/olhardeprofessor> 
Amancio Leandro Corrêa Pimentel, Antônia Solange Pinheiro Xerez e Francisco Mirtiel Frankson Moura Castro imersos na lógica capitalista de coisificação e proliferação de patologias. Freire não está ignorando o fato de que a realidade é feita de múltiplos elementos condicionantes estruturais. Ele evidencia, no entanto, esses aspectos, para que se reflita acerca do crescimento da pessoa e o poder de influência que as gerações mais velhas, e a legitimação de determinados comportamentos e atitudes, têm sobre as gerações mais jovens. Reflete, portanto, acerca do desafio a que pais, mães, professores, professoras devem assumir no cuidado e não abandono, o que nem sempre se verifica possível em consequência de múltiplos determinantes estruturais.

Tal comportamento condiz com a lógica do lucro, com a "ética" do mercado, conforme destaca Freire (2015), que passa a ver as pessoas como úteis ou não, afinal “[...] tocaram fogo no corpo do índio como quem queima uma inutilidade [...] o índio não era um tu ou um ele. Era aquilo, aquela coisa ali” (FREIRE, 20I5, p. 75). Portanto, uma vez que nossa sociedade está imersa nesse modus operandi do mercado, a educação deve se colocar como instrumento de luta pelos princípios e valores éticos mais profundos e de respeito à vida.

Nesse ponto, não ignoremos as "conversas" que - no início do atual do governo brasileiro estavam presentes em seu discurso, acerca da educação domiciliar. Para além dos aspectos de estimulo da educação e do conhecimento como mercadorias a serem vendidas no mercado - apostilas, videoaulas, professores particulares e recursos diversos - tal concepção, em se tornando prática generalizada, negaria às crianças a riqueza de momentos capazes de proporcionar a tão necessária formação ética e democrática.

São momentos de coletividade, de conflitos e suas resoluções, de estabelecimento de limites, respeito, de convivência com o diferente, com pares e com adultos diversos, dentre os quais professores, professoras, funcionários e funcionárias em geral, de estabelecimento de regras, de cooperação em apresentações, de trabalhos em equipe, da necessidade de escolhas, negações, rupturas etc.; ocasiões essas que se exprimem como imprescindíveis a um crescimento humano saudável e à formação de consciência democrática. Portanto, o apelo de Freire em 1997 se mantém pertinente: urge a necessidade de lutar por uma educação pública coletiva, que se estabeleça sobre valores e princípios da ética universal do ser humano, com vistas à constituição de outro mundo.

A formação de consciência ética e democrática não se dá necessariamente em aulas de ética e em aulas de relações interpessoais, mas em situações cotidianas, com a vigilância equilibrada de adultos e adultas, professores e professoras, nos conflitos espontâneos dessas relações, nos momentos de confronto ante situações de desrespeito, preconceito, violência física, psíquica ou simbólica. Diferentemente dos tigres, gatos e cachorros; as pessoas, superando o mero suporte, saltando qualitativamente para perceber o suporte como mundo, podem tomar distância para ver melhor; de 
O pensamento de Paulo Freire expresso na obra Pedagogia da Indignação: cartas pedagógicas e outros escritos ver e rever os passos, decisões, escolhas, certo, errado; de projetar antes de fazer; de construir e reconstruir, enfim, de educar e ser educado.

$\mathrm{Na}$ contextura dessa reflexão, Freire (2015) diz nada pensar sobre o "descobrimento" da América, quando convidado a propor reflexão sobre essa matéria, em 1992, num evento acerca do $V$ centenário da vinda dos europeus às terras denominadas América. No texto, Descobrimento da América, ele é enfático, ao dizer: “[...] não penso nada sobre o 'descobrimento' porque o que houve foi conquista. E sobre conquista, o meu pensamento em definitivo é o da recusa [...]" (FREIRE, 20I5, p. 84).

Esta configura uma obviedade: o que houve foi violência, invasão por parte de povos que se consideravam superiores a outros - ao modo da lógica dos adolescentes que estavam apenas brincando... De matar! Os extremos, tirania da liberdade e autoritarismo, se encontram em sua ânsia necrófila. Tal violência e invasão estão "molhadas" em um gosto incontido de se sobrepor ao outro, sobre diferentes, sobre "inferiores". Violência e invasão do corpo, do espaço físico, do espaço culturalsimbólico e espiritual.

Dentro desse trágico processo, Freire (2015) se recusa a encontrar qualquer positividade. Encontra-se, entretanto, um ensinamento daquilo que se deve realmente homenagear, comemorar e celebrar, que não é nem a invasão nem conquista, mas a rebeldia contra essa invasão e conquista. Rebeldia por parte dos indígenas e rebeldia por parte dos africanos escravizados na sua luta, nos quilombos - "[...] momento exemplar na luta dos conquistados [que] se repetem hoje nas lutas populares" (FREIRE, 20I5, p. 86).

As presenças do passado em nosso presente devem ser percebidas, Nossa história deve ser conhecida e com ela devemos aprender a não repetir erros e a resistir. Resistir à exploração, à retirada da liberdade, resistir a qualquer imposição e invasão. Tal aprendizado se faz cada vez mais necessário, pois nossa sociedade - ontem e hoje - se pauta pela lógica utilitária das supracitadas, coisificação e mercadorização de pessoas e natureza em geral. Não é por acaso que continuamos vivendo um tipo de colonização atual que se dá por uma dominação de classe, donde vem uma dominação econômica e cultural, inferiorizando povos que pensam diferente e, ainda, desrespeitando minorias culturais e étnicas pelo mundo.

Veja-se, dessa maneira, a mentalidade dos governantes atuais - inseridos no poder, contraditoriamente, pelo povo - que abertamente se posicionam contra reservas indígenas, fazem chacotas com quilombolas, mulheres, homossexuais e com a história, chegando a atenuar a culpa dos europeus na escravização de africanos ${ }^{4}$. $O$ que se tem aqui? $O$ arquétipo da formação de uma não

\footnotetext{
${ }^{4}$ Conferir a participação do atual Presidente do Brasil no programa Roda Viva da TV Cultura, exibido no dia 30 de julho de 2018.
}

Olhar de professor, Ponta Grossa, v. 24, p. I-2I, e-I6723.013, 2021.

Disponível em <https://revistas2.uepg.br/index.php/olhardeprofessor> 
Amancio Leandro Corrêa Pimentel, Antônia Solange Pinheiro Xerez e Francisco Mirtiel Frankson Moura Castro consciência democrática, bem como da distorção da ética. Ou seja, da incapacidade de saber lidar com a liberdade; da percepção da autoridade como autoritarismo; do entendimento da escolha, e da decisão como atos arbitrários.

\section{História, formulação da realidade e educação}

Dentro dessa reflexão, acerca da necessidade da formação, da elaboração de consciência democrática como elemento imprescindível, dentre outros, para a transformação e reinvenção do mundo, é preciso ter sempre em consideração o entendimento de que mudar é difícil, pode até parecer impossível, mas é possível. Somos sujeitos históricos, "[...] lutando por outra vontade diferente: a de mudar o mundo, não importando que esta briga dure um tempo prolongado, que, às vezes, nela sucumbam gerações" (FREIRE, 20I5, p. 69). O autor insiste, contudo, em que, mantendo o sonho e a esperança, é preciso ter em conta, tanto quanto a constatação da dificuldade, a constatação de que a realidade é histórica, portanto, não está acabada, mas em constante formulação, pois o mundo é feito por pessoas e por pessoas pode ser modificado, conforme acreditava e expressava Marx em sua terceira tese sobre Feuerbach, “[...] as circunstâncias são modificadas pelos homens” (MARX; ENGELS, 2007, p. 533). Portanto, é uma luta que precisa ser travada e, no segundo texto do livro, Do direito e do dever de mudar o mundo, Freire nos presenteia com alguns entendimentos fundamentais nessa luta.

O primeiro aspecto compreende a realidade como histórica. Não se há de perder a lucidez quanto à existência de presenças do passado no nosso presente. Freire expressa que o passado colonial, escravocrata e ditatorial, está no nosso presente, fazendo com que a realidade seja tão contraditória. "Não há hoje, por isso mesmo, que não tenha 'presenças' que, de há muito, perduram no clima cultural que caracteriza atualidade concreta. Daí a natureza contraditória e processual de toda a realidade" (FREIRE, 20I5, p. 62). Precisamente, entretanto, por ser a história contraditória, é que se põe a possibilidade de gestação do novo. Afinal, na medida em que o passado opressor ainda se encontra em nossa atualidade, a rebeldia e a resistência contra a opressão se mantêm, como, num exemplo, em movimentos que a rigor têm raízes em lutas do passado, dentre os quais, destaque-se o Movimento dos Sem-Terra (MST). Nessa convulsão de contradições, existem sonhos e contra-sonhos o tempo inteiro lutando para se estabelecerem.

Freire (2015) traz, pois, a educação como um espaço que oferece uma contribuição nesta luta por transformação. Ele parte, primeiro, da obviedade - não mais tão óbvia nos dias atuais - de que a educação não é neutra, de que essa possibilidade não existe. Ou a educação serve para manter as estruturas do jeito como estão, sem mexer nas estruturas que geram a injustiça e a desigualdade, ou a educação contribui para transformar.

Olhar de professor, Ponta Grossa, v. 24, p. I-21, e-16723.013, 2021.

Disponível em <https://revistas2.uepg.br/index.php/olhardeprofessor> 
O pensamento de Paulo Freire expresso na obra Pedagogia da Indignação: cartas pedagógicas e outros escritos

Assim, Freire (20I5) postula uma educação radical. Radical porque vai à estrutura e busca entender a razão de ser, ou seja, ele propõe que a educação deve, em seu trabalho com os conteúdos curriculares e conhecimentos historicamente acumulados, ir além do perfil do conteúdo, ou seja, que perceba o conteúdo, o tema, os assuntos em suas múltiplas facetas, transpondo sua representação fenomênica. Para ele a educação, educador, educadora, educando e educanda precisam se dispor a fazer um verdadeiro cerco epistemológico ao objeto de estudo, compreendendo que educação não é apenas se apropriar de conteúdo curricular, mas entender que se aprende conteúdo para que esse aprendizado sirva de contribuição na intervenção da realidade o que nos remete ao quinto texto da Pedagogia da indignação, Alfabetização e miséria. Nesse, Freire relata uma conversa que teve com um educador popular chamado Danilson, caminhando por uma favela em Olinda/Pernambuco. Enquanto tropeçavam "na dor humana" (FREIRE, 20I5, p. 85), eles se perguntavam acerca do que um educador e uma educadora, críticos, podem fazer numa comunidade assim. Pode ser feito algo além de transferir mecanicamente conteúdos?

$\mathrm{Na}$ formulação de respostas aproximativas a essas questões, o texto diz que a primeira dimensão que um educador precisa ter é a consciência de que o mundo, a realidade, a história não são coisas prontas e acabadas, ou seja, é algo problemático, é algo que está em andamento. Faz-se imprescindível ao educador e à educadora progressista "[...] o saber do futuro como problema e não como inexorabilidade. É o saber da História como possibilidade e não como determinação. O mundo não é. O mundo está sendo" (FREIRE, 20I5, p. 90). Está desse jeito hoje, mas poderia ser de outra maneira se os seres humanos tivessem estabelecido a realidade de outra maneira. Essa consciência é fundamental, pois coloca em tela algo que conservadores e reacionários não querem que o povo saiba: que as distintas realidades podem ser transformadas. Isso mantém a esperança e o sonho, tão necessários ao caminhar.

A segunda dimensão é que, na qualidade de professores e professoras, devemos estudar permanentemente. Freire diz: "[...] preciso ter e renovar saberes específicos em cujo campo minha curiosidade se inquieta e minha prática se baseia" (FREIRE, 2015, p. 91), mas o nosso estudo, a nossa dedicação ao estudo tem que ser fruto do nosso compromisso com a realidade, ou seja, não estudamos apenas para acumular conteúdo, somente por estudar. Estudamos porque nos comprometemos com a mudança da realidade. Se profissionais da alfabetização, devemos conhecer com precisão os mecanismos, teorias e práticas de alfabetização. Vejamos as palavras de Freire: "[...] como alfabetizar sem conhecimentos precisos sobre a aquisição da linguagem, sobre linguagem e ideologia, sobre técnicas e métodos do ensino da leitura e da escrita?" (FREIRE, 2015, p. 92). A atitude descrita se alonga a todas as áreas do saber História, Matemática, Geografia, Biologia, Filosofia, Sociologia..., nas

Olhar de professor, Ponta Grossa, v. 24, p. I-2I, e-16723.013, 2021.

Disponível em <https://revistas2.uepg.br/index.php/olhardeprofessor> 
Amancio Leandro Corrêa Pimentel, Antônia Solange Pinheiro Xerez e Francisco Mirtiel Frankson Moura Castro quais seus profissionais, sendo éticos e coerentes com seu sonho e discurso, precisam ser dedicados e competentes.

A terceira dimensão fundamental está no fato de que docentes, sem imposições, mas em diálogo devem desafiar as pessoas, principalmente dessas áreas de miséria, de violência e negação humana, a entenderem a realidade criticamente, entenderem que a realidade poderia ser outra, que as estruturas do mundo onde se vive é que geram as desigualdades e a negação humana. Nesse processo dialógico, ele diz, coloca-se como imprescindível, que entendamos como as pessoas percebem a realidade, pois só a partir daqui é possível fazer do processo educativo algo mais do que mera transmissão "pura" de conteúdos. Só a partir do conhecimento da percepção da realidade que tem as comunidades com que se trabalha é possível projetar e efetivar um trabalho pedagógico que, de fato, leve em consideração as pessoas e suas problemáticas reais, concretas, não para se limitar a tais questões, mas com base nelas, trazer os conteúdos como meio de análise e problematização da realidade local, nacional e internacional.

Ressaltamos, nesse ponto, que nunca se falou tanto em doutrinação ideológica como se tem falado desde 2004, com a criação do Escola sem Partido (PENNA, 2017), e, sobretudo, desde os processos eleitorais de 2018. E o "grande vilão doutrinador" é apontado como quem? Paulo Freire. Trata-se, entretanto, de uma interpretação forçada e ideológica. Embora ele, sendo coerente com sua fala de que não existe neutralidade, sempre tenha assumido um lado - o dos esfarrapados do mundo, contra a opressão - uma opção política de esquerda e uma perspectiva e sonho de mundo, socialistas, ele nunca disse que tais opções deveriam ser impostas aos educandos e educandas. Ao contrário, ele sempre fez duras críticas a atitudes de imposição, como, por exemplo:

Um dos equívocos funestos de militantes políticos de prática messianicamente autoritária foi sempre desconhecer totalmente a compreensão do mundo dos grupos populares. Vendo-se como portadores da verdade salvadora, sua tarefa irrecusável não é propô-la mas impô-las aos grupos populares. (FREIRE, 2015, p. 94-95).

Sua crítica ao não-diálogo, à imposição, à manutenção do silêncio do educando e da educanda e à manipulação que fere a consciência e a lucidez ante a realidade e os temas do mundo se dirigiram à classe dominante, detentora dos meios materiais de produção e midiáticos filiada a uma opção política liberal, conservadora, positivista, capitalista. E, mesmo que tal concepção seja ensinada nas escolas, na TV, nas igrejas, tal não é visto como doutrinação e manipulação ideológica, portanto, Freire sempre militou, sim, pelo conhecimento da realidade, radicalmente, em suas estruturas, em ultrapasse aos perfis memorizados dos conteúdos curriculares e, se tal conhecimento da totalidade leva a insatisfações e lutas sociais, sobretudo, das classes populares, é porque a legitimação hegemônica da classe dominante tem operado violência contra tais classes e elas têm o direito de conhecer a realidade e 
O pensamento de Paulo Freire expresso na obra Pedagogia da Indignação: cartas pedagógicas e outros escritos lutar. E aqui voltamos à necessidade de conhecer, perceber a história como possibilidade e não como fatalismo. Isso Freire sempre defendeu, porque, a rigor, isso é educação genuína.

Perceber a história como possibilidade, compreender nossa profissão como compromisso político-pedagógico, na busca por transformações dessa realidade, histórica, considerando as dificuldades locais, nacionais e internacionais como questões problemáticas e não inexoráveis, por isso, transformáveis, retroalimenta uma categoria que atravessa a obra de Freire. Esperança.

O que é esperança para Paulo Freire? Ele trabalha com esse conceito, no oitavo texto do livro, Educação esperança, com suporte na ligação dele com os conceitos de consciência, história e de responsabilidade ética. Para Freire (20I5), esperança está intimamente ligada à consciência. O que é consciência? Algo que nós temos e que o tigre, o gato, o cachorro não têm; a capacidade de tomar distância de algo para conseguir ver melhor, para conseguir perceber melhor, a capacidade de projetar antes de fazer. Isso, em síntese, é um dos atributos da consciência. Deste modo, Freire destaca: "Consciência do outro e de si como um ser no mundo, com o mundo e com os outros, sem a qual seria apenas um ser aí, um ser no suporte. Por isso, repita-se, mais do que um ser no mundo o ser humano se tornou uma presença no mundo [...]" (FREIRE, 20I5, p. 130). Na tomada de consciência, vai-se adquirindo os reconhecimentos de que somos seres inacabados, inconclusos e que, por isso mesmo, a história também não é algo acabado, dado e determinado.

Somente com amparo nesses reconhecimentos, e no entendimento da realidade como movimento e possibilidade, é que se exprime sentido à discussão sobre esperança. E é aqui que emerge o conceito de responsabilidade ética. Freire (2015) traz as seguintes questões: Se tudo fosse um destino dado, pré-estabelecido, qual seria o sentido da responsabilidade? Que sentido haveria em travar discussões e projeções acerca da ética? Que sentido haveria em pensar na reconstrução do mundo, no qual as bases poderiam ser o respeito, a solidariedade autêntica, a coletividade se tudo já estivesse finalizado?

É justamente porque somos inacabados; é justamente porque a história é possibilidade; é justamente porque somos presença na história, na realidade; é por tudo isso que se pode ter esperança de que as coisas possam mudar. Não é uma esperança que espera, mas uma esperança que se torna presença na história. Ser presença na história é agir nela, é se meter na história, é constatar para intervir na história. Isso é esperança em Paulo Freire. Portanto, esperança só se coloca como categoria realista na medida em que há permanente denúncia da violência gerada com base em nossos modelos de produção e sociabilidade e anúncio de novas possibilidades.

Denúncia e anúncio são categorias nas quais Freire se detém com mais vagar no último texto do livro, Denúncia, anúncio, profecia, utopia e sonho. Freire (2015) pensa no profeta como aquela pessoa que anuncia um futuro, que anuncia possibilidades; mas, nesse processo de anúncio, é preciso denunciar 
Amancio Leandro Corrêa Pimentel, Antônia Solange Pinheiro Xerez e Francisco Mirtiel Frankson Moura Castro o momento presente, o que nos remete aos profetas bíblicos, que, ao anunciarem algo do futuro, anunciavam o atual, o que se estava fazendo de errado no momento, e é justamente o que Freire nos chama para fazer.

Anuncie-se um futuro de possibilidades, transformado, pautado por outros valores, mas para isso é preciso denunciar o que tem de errado no momento. Para que se possa fazer, contudo, essa denúncia, é preciso ter uma intimidade com a nossa história, com a história humana até aqui. Ele diz: "Não há possibilidade de pensarmos o amanhã, mais próximo ou mais remoto, sem que nos achemos em processo permanente de 'emersão' do hoje, 'molhados' do tempo que vivemos, tocados por seus desafios, instigados por seus problemas [...]” (FREIRE, 20I5, p. I35). Impõe-se ter uma intimidade com o hoje para que se possa, então, projetar alguma coisa de novo, o diferente e, nesse processo de denúncia do hoje, do que está errado, ele diz que é preciso denunciar os valores que pautam a vida social, que doutrinam e manipulam pessoas, que baseiam a vida econômica.

Valores individualistas, gerados nas leis do mercado, do lucro sem freio, do "salve-se quempuder", do cada um por si, do vale tudo, isso precisa ser denunciado. É preciso denunciar uma perspectiva ideológica que se diz não ideológica e que, em razão disso, mata o sonho, a esperança, a perspectiva de mudança. É preciso denunciar, um saber que se diz neutro. É preciso denunciar para que se possa anunciar uma outra realidade, que não se paute pelo individualismo, mas, ao contrário, que se paute pela coletividade, pela solidariedade, uma economia que se assente em uma outra lógica que não seja a das leis neoliberais do mercado que preza por uma liberdade maldosa, licenciosa que termina por se alongar em uma ditadura de mercado à qual tudo deve se submeter.

Freire (2015) chega a tratar sobre a conveniente dificuldade, por parte dos entusiastas do mercado alienados em sua lógica, de compreensão - enfatize-se, conveniente incompreensão - de qualquer defesa da preponderância do humano em relação ao mercado. Ele diz: “[...] menos inteligível ainda se tornaria o discurso se seu sujeito se alongasse em considerações que, ultrapassando a estreita e perversa ética do mercado e do lucro, falasse na defesa da ética universal do ser humano" (FREIRE, 2015, p. I50). Aqui somos remetidos à reflexão do próximo e último momento de nosso estudo sintético.

Qual é a lógica hegemônica que vem estimulando e movimentando a globalização e a produção tecnológica, sobretudo a do setor dos meios de comunicação de massa, que veicula um saber para as massas, muitas vezes amorfas, por não terem o lastro e a liga produzida pela cultura popular organizada e crítica? (A do mercado). 
O pensamento de Paulo Freire expresso na obra Pedagogia da Indignação: cartas pedagógicas e outros escritos

\section{Globalização, tecnologia e educação}

Quais são os discursos que imperam na realidade capitalista? Um discurso arcaico e atual, um discurso que estimula a passividade, que conduz à adaptação, que instiga a imobilização das pessoas. Dentro desse discurso, difunde-se a perspectiva de que não existem mais lutas, não existem mais classes sociais. Quase que não existe mais política; só resultados. Não existe mais sonho, só o que pode ser constatado. Como se a realidade pudesse ser assim tão exata, tão técnica. No texto Desafios da educação de adultos ante a nova restruturação tecnológica, Freire diz que os avanços tecnológicos e a globalização, em si, não são negativos; mas há que se ficar atento "[...] ao uso político desses avanços por parte do poder econômico [...]" (FREIRE, 20I5, p. 106). Os avanços tecnológicos também são um bem da humanidade. Fruto da curiosidade humana, entretanto, a questão que precisa ser bem evidenciada é que tanto a globalização quantos os avanços tecnológicos vêm se dando dentro da perspectiva ideológica neoliberal da imobilidade, da passividade, da adaptação, da neutralidade, da despolitização da educação. Ele diz:

Este tipo de pragmatismo neoliberal a que mulheres e homens, ontem de esquerda, aderiram com entusiasmo se funda no seguinte raciocínio, nem sempre explícito: se já não há classes sociais, portanto seus conflitos também, se já não há ideologias, direita ou esquerda, se a globalização da economia não apenas fez o mundo menor mas o tornou quase igual, a educação de que se precisa hoje não tem nada que ver com ideologias, mas com saber técnico. A educação será tão mais eficaz quanto melhor treine os educandos para certas destrezas. Introduzir no ensino e no aprendizado da matemática, da física, ou no "treino" de operários qualificando-se o sonho da libertação, a utopia da justiça social é repetir erros funestos por causa dos quais pagamos caro. [...] $\bigcirc$ que vale mesmo é a realidade que é e não o sonho que joga com o que gostaríamos que fosse. A educação para hoje é a que melhor adapte homens e mulheres ao mundo tal qual está sendo. Nunca talvez se tenha feito tanto pela despolitização da educação quanto hoje (FREIRE, 2015, p. 108-109, grifo nosso).

Primeiramente, educação não é algo meramente técnico e mecânico. Educação, obviamente, tem relação com ciência, com técnica, mas também envolve ética, valores, política, agrega sonho, tem relação com a beleza, com a estética, com libertação, com ideologias - tem relação com classes sociais e seus conflitos. Freire (20I5) propõe e compreende o pensamento acerca da educação de um modo amplo. A educação precisa formar técnicos, cientistas, profissionais competentes, comprometidos coerentemente com suas atividades específicas, na mesma medida que deve formar pessoas críticas, atentas e lúcidas que possam submeter a globalização e os avanços tecnológicos à crítica, ao crivo do humano e da ética. A quem serve a tecnologia? A quem serve a globalização? Ao humano? Ao lucro? Ao mercado? A que classe social? Serve a libertação ou à opressão dominadora e violenta?

Portanto, a proposição de Freire (20I5) é a de que globalização e tecnologia são expressões do humano, portanto, em si, são positivas, pois partem da vitalidade humana, são frutos da curiosidade 
Amancio Leandro Corrêa Pimentel, Antônia Solange Pinheiro Xerez e Francisco Mirtiel Frankson Moura Castro humana. Como, porém, determinados aspectos na existência sociocultural não podem ser analisados com base no "em si", como se algo humano pudesse estar "puro" e isolado de percepções, juízos de valores, concepções ideológicas - como queria Durkheim (2007) nas Regras do método sociológico quando disse que era preciso, portanto, “[...] separar o fato social de toda mistura para observá-lo no estado de pureza" (DURKHEIM, 2007, p. 8) - torna-se imprescindível que se tenha lucidez ante o produto do humano. A quem serve a produção do trabalho humano?

Dentro dessa reflexão sobre o produto humano fruto natural da curiosidade humana, feito característica que torna o humano um ser genérico, para utilizar as palavras de Marx (2010), Freire, no texto Alfabetização em televisão, enfatiza acerca dessa categoria que nos move: a curiosidade. $O$ humano é curioso. Nossos filhos e filhas, as crianças em geral são curiosas. Freire (2015) traz o destaque de que no processo de crescimento e desenvolvimento, quando se vai atingindo tempo de vida, essa curiosidade tem que ir também se "criticizando." Ele diz que, "[...] na medida em que a curiosidade ingênua, sem deixar de ser curiosidade, se criticiza. [...] tornando-se, então curiosidade epistemológica rigorizando-se na sua aproximação ao objeto, conota seus achados de maior exatidão" (FREIRE, 20I5, p. I22).

Para que essa curiosidade crítica? Para que esse conhecimento menos caótico e mais preciso (não acabado ou fechado)? Para aprender a se defender das armadilhas dos '“irracionalismos' decorrentes ou produzidos por certo excesso de 'racionalidade' de nosso tempo altamente tecnologizado. Mas não vai nesta consideração nenhuma arrancada falsamente humanista de negação da tecnologia e da ciência" (FREIRE, 20I5, p. 123). Por vezes, com os avanços tecnológicos, a TV, a internet e todas as evoluções nos meios de comunicação, informação e entretenimento, coloca-se uma percepção de fundo, sutil, mas eficaz, de que essas coisas podem quase que substituir o humano, a subjetividade humana, o sonho, as ideologias humanas, os processos humanos na sua expressão política etc.

$\mathrm{Na}$ percepção de muitos e muitas, é como se a produção tecnológica estivesse isenta de paixões, de ideologias, de política, separada de toda mistura (DURKHEIM, 2007). É como se a tecnologia fosse um ente que se reproduz por si, resguardado das intenções humanas. Isto, no entanto, é uma falácia. Tudo é político. Não há neutralidade. Tudo tem uma ideologia, um modo de ver e uma cosmovisão. Então, é preciso ser crítico e lúcido para se defender desses irracionalismos, sem negar, como citado, a tecnologia, o novo ou a ciência.

O segundo ponto desse irracionalismo é que às vezes se aceita, então, tudo o que é veiculado pela tecnologia como se fosse uma verdade absoluta. Ou seja, mantemos o gosto pelo novo, o gosto pela curiosidade, o gosto pelos avanços, mas de modo crítico. Não se trata de negar. É o caso de desenvolver uma perspectiva desperta e lúcida diante de um instrumento a ser utilizado em prol do

Olhar de professor, Ponta Grossa, v. 24, p. I-2I, e-16723.013, 2021.

Disponível em <https://revistas2.uepg.br/index.php/olhardeprofessor> 
O pensamento de Paulo Freire expresso na obra Pedagogia da Indignação: cartas pedagógicas e outros escritos humano, da vida, da ética ou em seu detrimento, que pode ser usado para libertação e transformação da realidade e das pessoas ou para sua manipulação e conservação do mundo como está.

Enfim, Freire (2015) convoca educadores e educadoras a se apropriarem dos avanços tecnológicos, a se acercarem do novo, não para aderirem ao "novo" só porque é "novo". Estimula trabalhadores e trabalhadoras da educação a buscarem recursos diversos para otimizar seu trabalho, sem necessariamente, abandonar o "velho", só porque é "velho". O desafio proposto é o de que, lúcidos e despertos, conheçamos os processos tecnológicos, usemos, se possível, e, sobretudo, discutamos o que tais processos veiculam - daí a importância de ser estudada a obra em discussão neste artigo e outras de Paulo Freire.

\section{Considerações finais}

A leitura de Paulo Freire, desde seus primeiros escritos, sempre esteve embebida dos temas do momento histórico atual, sobre os quais se colocavam suas análises e reflexões. A necessidade de conhecer o hoje com seus desafios, conflitos e possibilidades atravessa toda sua obra, deixando-nos um legado e uma provocação no prosseguimento da leitura do mundo que precede a leitura da palavra, mas que não prescinde dela. Afinal o conhecimento da palavra escrita, do saber epistemológico, sistematizado pela humanidade, como continuidade e busca da superação do saber e curiosidade ingênua traz maiores exatidões e rigor à leitura e interpretação da realidade.

Freire disse que, nos anos 1990, nunca se fez tanto pela despolitização da educação e, sete anos depois de sua partida, funda-se no Brasil um movimento - Escola sem partido - que, pautado pelo Código de Defesa do Consumidor (PENNA, 2017) - se propõe exorcizar da educação qualquer ideia de percebê-la em conexão com a realidade, apelidando conveniente e falaciosamente tal prática de prática educativa partidária de esquerda, doutrinadora, gerando confusão com o proposto por Paulo Freire.

Estamos vivendo momentos de exacerbação de um tipo de positivismo-tecnicista conservador, ideológico ao extremo, sob o discurso insistente de ser não ideológico, e autoritário em nome de estar filiado em uma perspectiva "moderna" assentada por "evidências científicas”, expressão utilizada à exaustão na Política Nacional de Alfabetização - PNA (BRASIL, 2019) em detrimento da educação em sua amplitude e complexidade, operando assim uma redução desta.

Hoje, mediante a generalização acentuada de notícias falsas, disseminadas em variadas redes sociais e de seu poder de influência, a reflexão trazida na Pedagogia da indignação se faz mais pertinente ainda, uma vez que conhecer o presente, a história, as presenças do passado no presente, manter-se desperto, atento e lúcido é, em destaque, a principal maneira de combater a mentira como legitimação. O compromisso ético-político-cidadão com o conhecimento, com a valorização dos 
Amancio Leandro Corrêa Pimentel, Antônia Solange Pinheiro Xerez e Francisco Mirtiel Frankson Moura Castro saberes em sua amplitude, defendido na obra, nos leva a recomendar a leitura do referido livro como fundamento teórico-epistemológico e meio para leitura e análise do cenário contemporâneo político e histórico do Brasil.

Perceber a história como possibilidade e não como fatalismo ou determinismo nos deve animar em meio ao caos político que vivemos, que, às vezes, parece ter ares de eternidade. A percepção do inacabamento do humano e da história conduz a uma reflexão que alimenta a luta esperançosa pelo estabelecimento verdadeiramente ético, arrimado no humano e para o humano, do mundo, que fazem - pensamento de Freire se expressar ainda mais como atual e necessário para a sociedade contemporânea. Afinal, atualmente se verifica a proliferação e legitimação de discursos antidemocráticos em que se negam o diálogo e a exposição ao contraditório em que autoridade se confunde com autoritarismo, liberdade com licenciosidade e a ética é distorcida em adequação à lógica de mercado.

Além do mais, sob a falácia de que o futuro é inexorável e não problemático, estimula-se e acredita-se que o atual modelo de sociabilidade, assente no autoritarismo, na licenciosidade e distorção da ética humana é o que se tem, e o máximo que se poderá fazer é minimizar os efeitos fenomênicos, sem transformações nas causas estruturais, inviabilizando o sonho e a esperança de outro modelo de sociabilidade. Freire (1980, p. I I0), na Pedagogia do oprimido diz que dentro dessa percepção imersa na ideologia fatalista os homens e mulheres “[...] não chegam a transcender as 'situações-limites' e descobrir ou divisar, mais além delas, e em relação com elas, o inédito viável”. Aqui percebemos em sua coerência entre os primeiros e últimos escritos sua pertinente defesa de que outra realidade deve ser constituída com a participação ativa do povo, dos oprimidos e das oprimidas, da classe trabalhadora.

Tal participação implica em, antes de tudo, obter conhecimento lúcido dos temas vigentes, dos discursos a eles aderidos. Tal participação ativa significa ser presença na história. Ser presença na história demanda se apropriar das construções do trabalho humano, que são fruto de sua inquietação e curiosidade. Portanto, apreender o conhecimento historicamente acumulado e sistematizado, as tecnologias, os meios de comunicação, os mecanismos ideológicos por eles veiculados, com vistas a problematizá-los, debatê-los, denunciá-los quando usados para opressão e conhecidos para uso competente com vistas à permanente tomada de consciência, faz-se urgente.

Em toda essa reflexão - sobre democracia, ética, história, construção de outro modelo de sociabilidade, conhecimento e problematização das tecnologias e dos meios de comunicação, bem como dos discursos ideológicos a eles aderidos - tudo constante na Pedagogia da indignação, Freire (2015) situa a educação como espaço privilegiado para a veiculação e problematização de tais temas. Sua defesa é a de que, esses assuntos estão intrinsecamente relacionados aos conteúdos curriculares, todavia, em geral, permanecem intocados, pois, para a eles se chegar é imprescindível uma percepção 
O pensamento de Paulo Freire expresso na obra Pedagogia da Indignação: cartas pedagógicas e outros escritos radical que, procurando ir além do perfil do conteúdo, busque suas relações complexas com a realidade abrangente.

Portanto, no momento atual em que essas matérias afloram com novo vigor, sob discursos legitimados por grande parte da sociedade, as análises de Freire expressas na obra destacada, bem como em toda a sua produção, oferece contribuição e meio para análise de nossa sociedade e instrumentalização para nos subsidiar em nossas intervenções abrangentes, como cidadãos e cidadãs, bem como na qualidade de educadores e educadoras.

Ao considerar que a obra de Freire oferece subsídios à leitura constante da realidade, colocase como interessante e instigante a realização de estudos posteriores que busquem constituir relações das primeiras e últimas obras de Freire com vistas à captação e análise de sua inter-relação, relevância e constante atualidade. Nos dias atuais, em que Freire é atacado explicitamente, tais releituras se colocam como um necessário serviço prestado ao esclarecimento e ao desvelamento de sua teoria e prática transformadora, no sentido de operar em favor de um rompimento com a cadeia de incompreensões teóricas e ideológicas deste autor.

\section{Referências}

BRASIL. Ministério da Educação. Secretaria de alfabetização. PNA: Política Nacional de Alfabetização. Brasília: MEC; SEALF, 2019.

DESLANDES, S. F. et al. Pesquisa social: teoria, método e criatividade. Petrópolis, RJ: Vozes, 1994.

DURKHEIM, E. As regras do método sociológico. 3. ed. São Paulo: Martins Fontes, 2007.

FREIRE, P. Pedagogia do oprimido. 8. ed. Rio de Janeiro: Paz e Terra, 1980.

FREIRE, P. Educação como prática da liberdade. I2. ed. Rio de Janeiro: Paz e Terra, I98I.

FREIRE, P. Ação cultural para liberdade e outros escritos. I4. ed. São Paulo: Paz e Terra, 20I la.

FREIRE, P. Pedagogia da esperança: um reencontro com a Pedagogia do Oprimido. São Paulo: Paz e Terra, 20l lb.

FREIRE, P. Educação e mudança. 36. ed. São Paulo: Paz e Terra, 20I4a.

FREIRE, P. Pedagogia da indignação: cartas pedagógicas e outros escritos. 2. ed. São Paulo: Paz e Terra, 2015.

LAKATOS, E. M.; MARCONI, M. de A. Fundamentos da metodologia científica. 5. ed. São Paulo: Atlas, 2003. 
MARX, K.; ENGELS, F. A ideologia alemã: crítica da mais recente filosofia alemã em seus representantes Feuerbach, B. Bauer e Stirner, e do socialismo alemão em seus diferentes profetas. São Paulo: Boitempo, 2007.

MARX, K. Manuscritos econômico-filosóficos. São Paulo: Boitempo, 2010.

PENNA, F. A. O Escola sem Partido como chave de leitura do fenômeno educacional. In: FRIGOTTO, G. (Orgs.). Escola "sem" partido: esfinge que ameaça a educação e a sociedade brasileira. Rio de Janeiro: UERJ; LPP, 2017.

Recebido em: 24 de agosto de 2020.

Versão corrigida recebida em: 19 de novembro de 2020

Aceito em: 07 de dezembro de 2020.

Publicado online em: 19 de março de 2021 . 